\title{
Impacts of high-intensity storms on urban transportation: applying traffic flow control methodologies for quantifying the effects
}

\author{
E. Mitsakis • I. Stamos • M. Diakakis • \\ J. M. Salanova Grau
}

Received: 29 November 2013/Revised: 4 March 2014/ Accepted: 17 March 2014/Published online: 10 April 2014

(C) Islamic Azad University (IAU) 2014

\begin{abstract}
Urban flooding is becoming increasingly destructive in the Mediterranean region as more and more urban infrastructure and socioeconomic activities are exposed to flood risk. The metropolitan area of Athens, Greece, is no exception to this flood-prone regime, presenting a rich record of flood events during the last century. On February 22, 2013, a high-intensity storm that lasted $7 \mathrm{~h}$ hit Athens, severely impacting the transportation sector, hindering vehicle circulation and the overall performance of the road network. This paper studies the impacts of high-intensity storms in urban areas by examining the effects of the February 2013 Athens storm and the resultant flood event. Its novelty lies in the impacts quantification approach, applying cutting-edge traffic flow control methodologies in the form of macroscopic fundamental diagrams. It quantifies the storm's impacts on vehicular traffic in terms of operational disruptions during the event, by analyzing various traffic-related indicators, such as travel time, delays, speed drop and re-routing of vehicles, using data from the Athens traffic management center and urban freight vehicle fleets. Results show increased travel times, significant changes in routing and substantial speed drops, highlighting the disruptive effects of the flooding event on traffic. The importance of developing a qualitative and quantitative understanding of the
\end{abstract}

E. Mitsakis · I. Stamos $(\bowtie)$ · J. M. Salanova Grau

Centre for Research and Technology Hellas, Hellenic Institute of

Transport, 6th Km Charilaou-Thermi Rd., 57001 Thermi,

Thessaloníki, Greece

e-mail: stamos@certh.gr

M. Diakakis

Faculty of Geology and Geo-Environment, National and Kapodistrian University of Athens, Panepistimioupoli Zografou, 15784 Athens, Greece effects of such events in urban areas is particularly high, considering the context of the changing climate and the increasing frequency and intensity of extreme weather events.

Keywords Flooding - Urban transportation - Urban freight transport $\cdot$ Climate change $\cdot$ Extreme weather events $\cdot$ Traffic flow control

\section{Introduction}

The predicted increase in the frequency of extreme weather events (EWE) due to climate change has been studied in the literature, mostly focusing on detailed statistical analyses of extreme weather and climate event trends based on observations (Rosenzweig et al. 2001; Monirul and Mirza 2003; Meehl et al. 2000; Easterling et al. 2000; Amin et al. 2013). Findings show that the impacts of climate change might become more severe in the coming years, due to the increasing frequency of EWE rather than due to the overall change of the "average" climate (Mitsakis et al. 2013). Particularly within the context of the projected increase in the mean precipitation intensity and the probability of extreme rainfall across most of Europe (Dankers and Hiederer 2008), the analysis of the impacts of hydrometeorological phenomena in major urban centers becomes highly important.

Flooding is often the result of such EWE, leading to extensive economic damages, numerous fatalities and significant impacts on property and infrastructure (Barredo 2007, 2009; Jonkman 2005; Baloch et al. 2014). Especially in urban environments, where the concentration of population is higher, vulnerability to floods is increased, as the literature suggests that poorly planned development limits 
the capacity of the natural drainage network and decreases the water infiltration rate (James 1965; Hollis 1975; Bailey et al. 1989; Paul and Meyer 2001). Furthermore, flooding has the potential to disrupt social groups and economic sectors outside the actual flooded areas. Transportation of people and goods is among these sectors, as flooding directly impacts transport infrastructure and the circulation of vehicles, disrupting normal traffic operations (Suarez et al. 2005; Sohn 2006; Chang et al. 2010).

Interest in the effects of extreme weather conditions on traffic activity rose in the late 1970s, when it was observed that such conditions have a considerable impact on the overall traffic activity (Road Research Laboratory 1965). Later studies revealed that mode-switching (from public transport or walking to private vehicle use) and trip cancelations are directly related to adverse weather conditions, in addition to changes reported in a series of travel-related parameters: departure time, travel time and destination of trips (Hassan and Barker 1999; Mitsakis et al. 2014). In general, there are three predominant traffic-related areas that weather conditions have an impact on (Maze et al. 2006):

- Traffic demand-travelers might defer or cancel journeys

- Traffic safety-studies reveal that the risk of being involved in a car accident is up to 25 times higher
Table 1 Literature findings on vehicle flow reduction and speed drop due to rainfall

\begin{tabular}{|c|c|c|c|}
\hline Researcher & $\begin{array}{l}\text { Study } \\
\text { location }\end{array}$ & $\begin{array}{l}\text { Vehicle flow } \\
\text { reduction }\end{array}$ & $\begin{array}{l}\text { Vehicle } \\
\text { speed drop }\end{array}$ \\
\hline $\begin{array}{l}\text { Ibrahim and Hall } \\
\text { (1994) }\end{array}$ & Canada & $10-20 \%$ & $\begin{array}{l}\text { Up to } \\
10 \mathrm{~km} / \mathrm{h}\end{array}$ \\
\hline $\begin{array}{l}\text { Brilon and Ponzlet } \\
\text { (1996) }\end{array}$ & Germany & Up to $8 \%$ & - \\
\hline Maze et al. (2006) & USA & Up to $22 \%$ & Up to $6 \%$ \\
\hline Sabir et al. (2008) & Netherlands & - & $10-15 \%$ \\
\hline $\begin{array}{l}\text { Koetse and Rietveld } \\
\text { (2009) }\end{array}$ & USA & - & Up to $25 \%$ \\
\hline $\begin{array}{l}\text { Transportation } \\
\text { Research Board } \\
(2010)\end{array}$ & USA & - & $\begin{array}{l}\text { Up to } \\
32 \mathrm{~km} / \mathrm{h}\end{array}$ \\
\hline $\begin{array}{l}\text { Skabardonis et al. } \\
\text { (2013) }\end{array}$ & USA & Up to $14 \%$ & - \\
\hline $\begin{array}{l}\text { Skabardonis et al. } \\
\text { (2013) }\end{array}$ & Greece & Up to $16 \%$ & - \\
\hline
\end{tabular}

(Eisenberg and Warner 2004; Norrman et al. 2000; Perry and Symons 1991)

- Traffic operations and flow

Heavy rainfall and flooding impact traffic circulation by significantly reducing visibility and vehicle performance, while hindering traffic operations by increasing the accident
Fig. 1 a Map illustrating the locations of rain-gauges across the Athens basin and the distribution of total rainfall during February 22, 2013, storm event and, $\mathbf{b}$ the rainfall record of three characteristic raingauges in the western, central and northeastern part of the basin

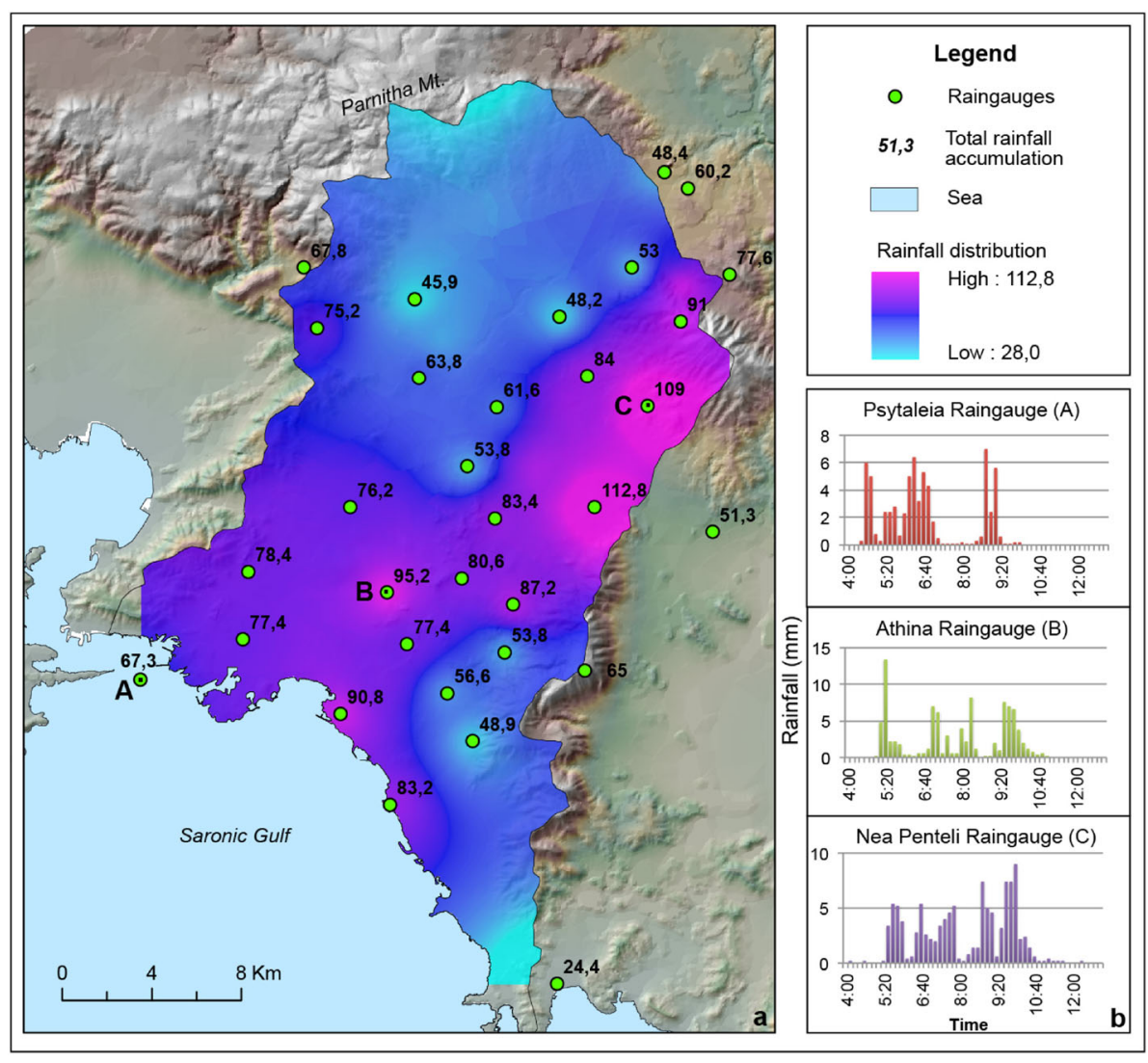




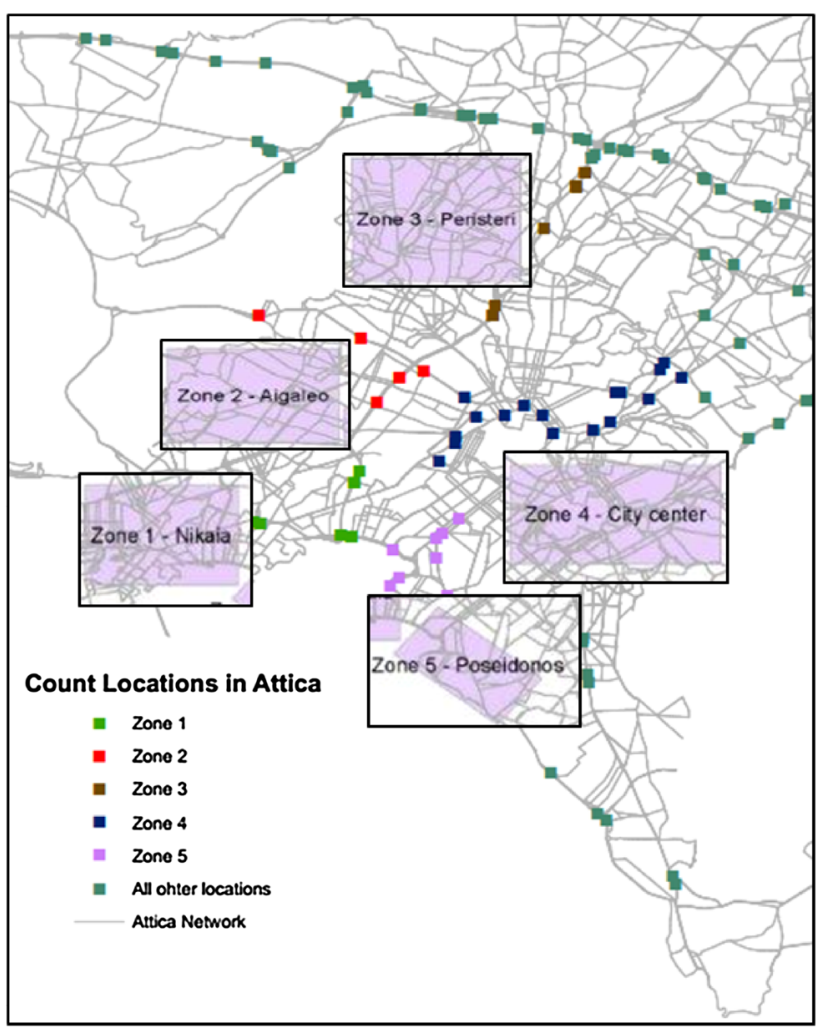

Fig. 2 Count locations within the Athens road network

risks and reducing vehicle speed and roadway capacity (Goodwin 2002). Table 1 summarizes recent findings regarding the quantification of these reductions. As observed, rainfall can induce a traffic flow decrease of up to $22 \%$, while the presence of rain regardless of intensity can result in an average decrease of up to $25 \%$ in operating vehicle speeds.

Yet to the authors' knowledge, no universal methodology for quantifying the impacts of EWE exists in the literature, rendering approaches used so far neither transferable nor easily applicable to other cases. The objective of this paper is to explore the impact of highintensity storms on transportation in the complex environment of a metropolitan area, by applying latest advances in the field of traffic flow theory and control [in the form of macroscopic fundamental diagrams (MFDs)]. The February 2013 Athens storm is used as a case study. Its impacts are quantified by measuring the disruptions in the circulation of urban and freight transport vehicles and by analyzing various traffic-related indicators, such as traffic flow, occupancy, vehicle speed and re-routing of vehicles.

Study area

Athens is the largest urban settlement in Greece, built in a morphologic basin formed by Penteli, Parnitha, Ymittos and Aigaleo mountains and Saronikos Gulf to the south, which contains the Kifissos and Ilissos drainage networks. The area is relatively dry (Mimikou et al. 2002) with a mean annual rainfall of approximately $390 \mathrm{~mm}$ (Koutsoyiannis and Baloutsos 2000). During the last century, Athens has been a rapidly evolving urban center, leading to a gradual urbanization of a significant part of the basin. Several parts of the Athens drainage network were diminished or even converted into streets (Mimikou et al. 2002; Baltas and Mimikou 2002; Alexouli-Livaditi et al. 2007), which together with the increasing impermeable surfaces have rendered Athens among the most flood-prone areas within Greece (Diakakis 2013; Diakakis et al. 2011). These effects contributed to a rich flooding record during the last century, presenting at least 52 major flooding events (Nikolaidou and Hatzichristou 1995; Diakakis 2013) and noteworthy fatalities (Diakakis et al. 2013), especially in vehicle-related flood incidents (Diakakis and Deligiannakis 2013).

The 2013 flooding event

In the early morning of February the 22nd, 2013, a storm started over the Athens basin as a result of a low barometric, which moved northeast from the shores of Northern Africa towards the southern Ionian Sea and subsequently to Athens, transferring a considerable amount of African dust. As a consequence, by the noon of Thursday the $21 \mathrm{st}$, most of the country experienced a hot weather front, along with rainfalls, which were most notable in the northern parts. Until the late evening of the day before (21/02), there was no storm outbreak reported over Athens, which highlights the fact that a cold front was either absent or inactive. However, during the night of the 21st, the increased transmission of perpendicular positive vortices and the atmospheric instability caused the activation of the cold front just after 4:00 a.m. (Lagouvardos et al. 2013). After the first hour of the storm over Athens (shortly before 5:00 a.m.), cool air masses were confined to the lower atmospheric layers, creating the conditions for strong upward movements that triggered more precipitation. The system was trapped over Athens basin for a prolonged period of time, leading to a re-feeding phenomenon and resulting in increased rainfall (amounts) (Lagouvardos et al. 2013). Although precipitation was firstly recorded in the western part of the city, the system expanded eastward relatively quickly, affecting the central and northeastern parts of Athens basin. These phenomena were accompanied by greatly increased electrical activity, high winds and hail.

\section{Materials and methods}

Weather-related data

The flooding event was recorded in at least 32 weather stations across the Athens basin, including the monitoring 
Zone 1
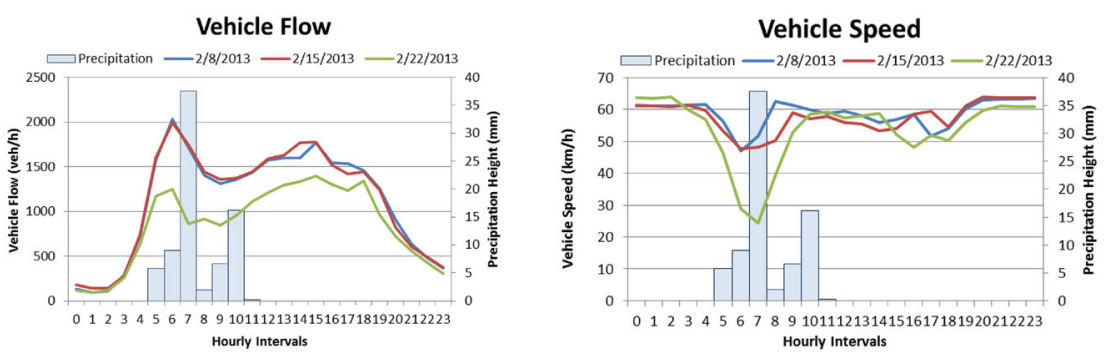

Zone 2
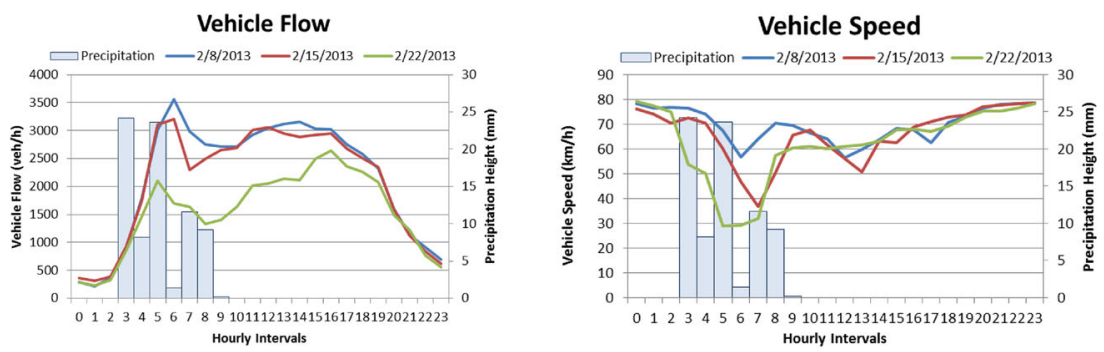

Zone 3

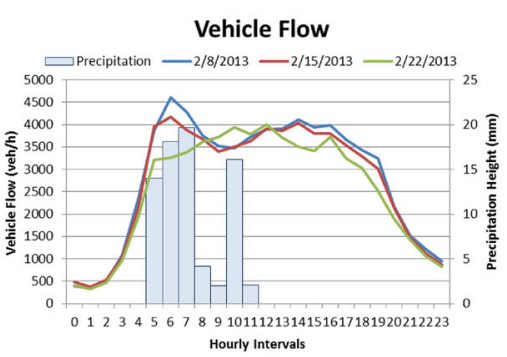

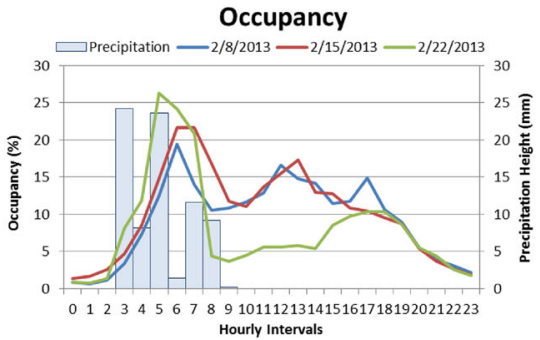

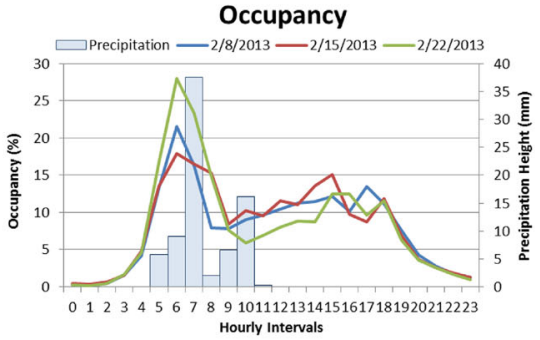

Houry intervals

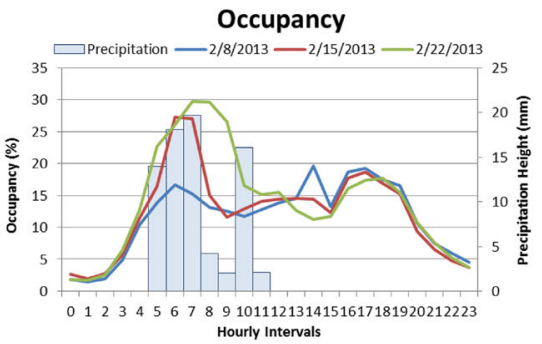

Fig. 3 Vehicle flow-speed and occupancy variations within the 3 days of analysis in a 24 hourly interval

network of the National Technical University of Athens and that of the National Observatory of Athens (Fig. 1). The quality of data collected from the weather stations was checked for missing values or inconsistencies through quality and homogeneity controls. The weather stations used were chosen, so as to obtain a maximum spatial coverage of the study area and to ensure satisfying documentation of the spatial variability of rainfall. Data were available in 10-min time-steps, providing both the intensity and the total rainfall amounts that were recorded during the storm.

The analysis time period considers three daily intervals, including two Fridays prior to the one of the flooding occurrence (08, 15 and 22/02/2013).

\section{Traffic-related data}

As a first step, documentary data regarding the effects of the storm and the resultant flooding on the road network of Athens were collected from the press and electronic media, in an effort to develop a systematic record of the event's impacts on the overall road transport sector and to identify the regions that were mostly affected. The analyses presented next focus on geographical zones within the Athens road network that were mostly affected by the flooding event. Traffic data were obtained from field detectors (inductive loops) of the Athens traffic management center, measuring vehicle flow, speed and occupancy. A total of 219 field detectors were used for the analysis, distributed within the zones previously identified as mostly affected by the event. The count locations and the respective zones are depicted in Fig. 2.

In order to quantify the flooding impacts on the traffic flow relationships in the Athens road network, an analysis was conducted based on the MFDs (vehicle flow vs. vehicle speed vs. occupancy) for the three examined days. As MFDs exist at a network level only when congestion is considered to be homogeneous over an area (Geroliminis and Daganzo 2007), data from detectors located within the same zone were grouped and analyzed.

In addition, Floating Car Data (FCD), obtained from freight vehicle fleets, were analyzed, in order to determine the extent to which freight transport was hindered during the flooding of February the 22nd, 2013, with regard to freight vehicles' speed 

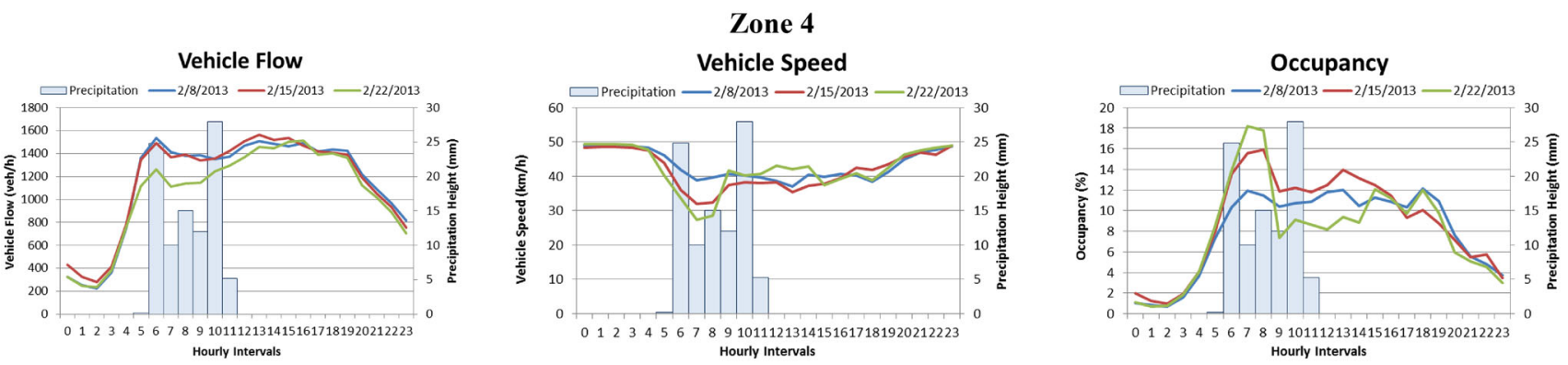

\section{Zone 5}
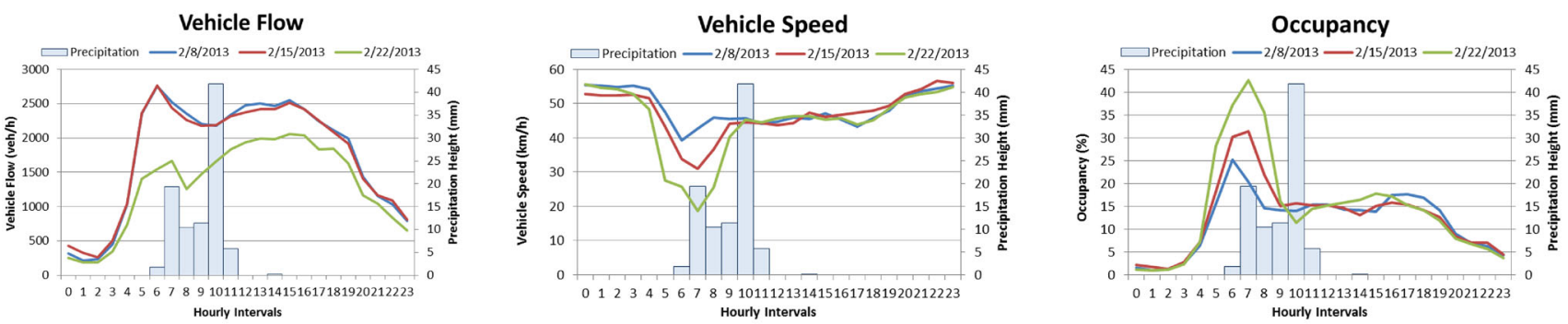

All other count locations
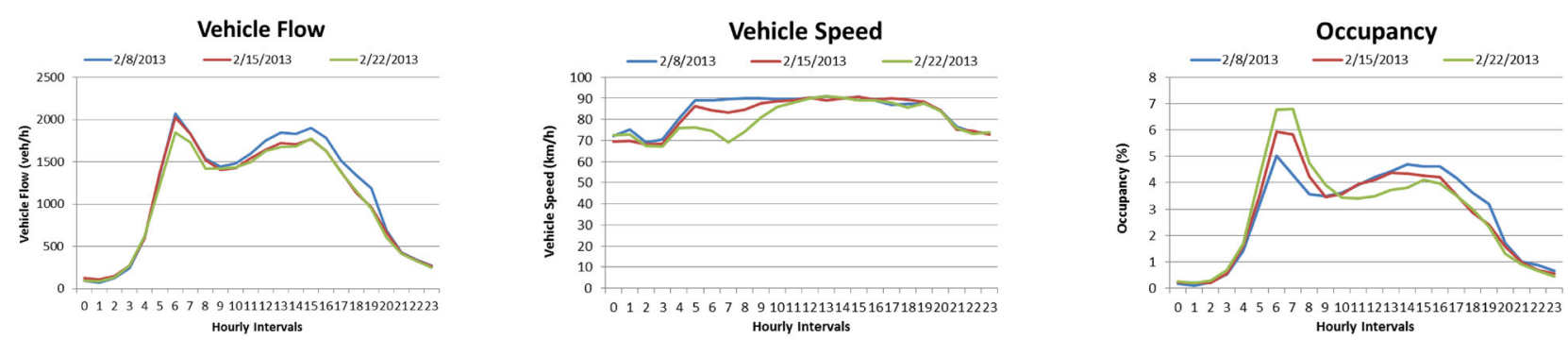

Fig. 4 Vehicle flow-hourly speed and occupancy variations within the 3 days of analysis

drop and changes in the usual course of vehicles (detours). The FCD databases contain GPS coordinates and speed information for freight vehicles during February 2013.

\section{Results and discussion}

A large number of commuters were exposed to the impacts of the high-intensity storm and the ensuing flooding, with many of them trapped in their vehicles or in standstill traffic due to intense traffic jams. During the event, a woman died of heart attack in her vehicle, which was found on a flooded road in the northern part of the city. By the end of the event, the fire service and other rescue teams received at least 1.675 calls from people, whose residencies were flooded and needed to be safely evacuated or whose vehicles were overturned or swept away by water (Fire Service 2013).

Impacts on the transportation network

Vehicle circulation along the main road axes and highways was hindered as water overflows caused disruptions in the operation of private and public transport. Two subway stations were closed during the heavy rainfall and there were several problems reported regarding the operation of the Athens tram, which was shut down for more than an hour, while scheduled urban rail services were also disrupted. Limited disruptions have also been reported regarding ferry operations.

The analysis of the traffic data collected from field detectors concerned the impact quantification of the event. Figures 3 and 4 depict the variations due to the heavy rainfall in the following traffic-related parameters: vehicle flow, vehicle speed and occupancy. Table 2 presents the maximum percentage change in the three analyzed parameters.

As shown, there is a clear tendency of reduction in vehicle flow, speed and occupancy in all zones, although the magnitude differs, based on the severity and the duration of the event in each zone. Although the analyzed parameters are theoretically linearly related to each other (vehicle flow equals speed multiplied by occupancy), fluctuations in the average, maximum and minimum values 
Table 2 Impact of flooding event on traffic-related parameters

\begin{tabular}{|c|c|c|c|c|c|c|}
\hline & \multicolumn{3}{|c|}{ Average daily vehicle flow (veh/h) } & \multirow[t]{2}{*}{ Average daily difference $(\%)$} & \multirow{2}{*}{$\begin{array}{l}\text { Average difference } \\
\text { during the event }(\%)\end{array}$} & \multirow{2}{*}{$\begin{array}{l}\text { Maximum difference } \\
\text { during the event (\%) }\end{array}$} \\
\hline & $8 / 2 / 2013$ & $15 / 02 / 2013$ & $22 / 02 / 2013$ & & & \\
\hline Zone 1 & 1,122 & 1,131 & 851 & -24.5 & -25.9 & -50.6 \\
\hline Zone 2 & 2,149 & 2,069 & 1,547 & -26.6 & -30.4 & -52.3 \\
\hline Zone 3 & 2,830 & 2,735 & 2,557 & -8.1 & -7.3 & -29.3 \\
\hline Zone 4 & 1,145 & 1,154 & 1,060 & -7.8 & -8.2 & -21.2 \\
\hline Zone 5 & 1,756 & 1,748 & 1,315 & -24.9 & -26.3 & -46.5 \\
\hline \multirow[t]{3}{*}{ Athens region } & 1,139 & 1,083 & 1,052 & -5.3 & -5.0 & -13.9 \\
\hline & \multicolumn{3}{|c|}{ Average daily speed $(\mathrm{km} / \mathrm{h})$} & \multirow[t]{2}{*}{ Average daily difference $(\%)$} & \multirow{2}{*}{$\begin{array}{l}\text { Average difference during } \\
\text { the event }(\%)\end{array}$} & \multirow{2}{*}{$\begin{array}{l}\text { Maximum difference } \\
\text { during the event (\%) }\end{array}$} \\
\hline & $8 / 2 / 2013$ & $15 / 02 / 2013$ & $22 / 02 / 2013$ & & & \\
\hline Zone 1 & 58.8 & 57.7 & 53.9 & -7.6 & -11.5 & -52.9 \\
\hline Zone 2 & 69.8 & 66.0 & 62.5 & -7.9 & -11.3 & -57.1 \\
\hline Zone 3 & 66.4 & 61.7 & 58.6 & -8.5 & -10.2 & -50.1 \\
\hline Zone 4 & 43.2 & 41.8 & 42.3 & -0.4 & -1.7 & -29.8 \\
\hline Zone 5 & 48.6 & 47.2 & 44.7 & -6.7 & -11.0 & -56.2 \\
\hline \multirow[t]{3}{*}{ Athens region } & 84.0 & 82.6 & 80.1 & -3.8 & -5.6 & -22.9 \\
\hline & \multicolumn{3}{|c|}{ Average daily occupancy } & \multirow[t]{2}{*}{ Average daily difference $(\%)$} & \multirow{2}{*}{$\begin{array}{l}\text { Average difference during } \\
\text { the event }(\%)\end{array}$} & \multirow{2}{*}{$\begin{array}{l}\text { Maximum difference } \\
\text { during the event }(\%)\end{array}$} \\
\hline & $8 / 2 / 2013$ & $15 / 02 / 2013$ & $22 / 02 / 2013$ & & & \\
\hline Zone 1 & 7.9 & 8.2 & 8.2 & 2.0 & 3.4 & 86.9 \\
\hline Zone 2 & 9.3 & 10.1 & 8.0 & -17.8 & -21.9 & -74.1 \\
\hline Zone 3 & 11.6 & 12.4 & 14.0 & 17.1 & 20.4 & 88.2 \\
\hline Zone 4 & 8.0 & 8.9 & 8.0 & -5.3 & -4.0 & 55.6 \\
\hline Zone 5 & 11.8 & 12.7 & 14.4 & 17.6 & 23.4 & 43.9 \\
\hline Athens region & 2.8 & 2.8 & 2.8 & 0.6 & 2.2 & 58.1 \\
\hline
\end{tabular}

\section{Zone 1}
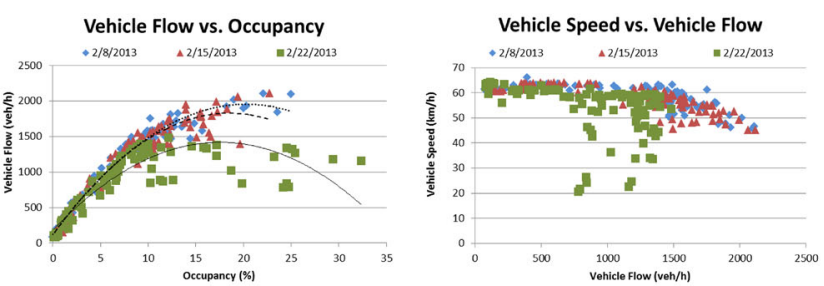

Zone 3
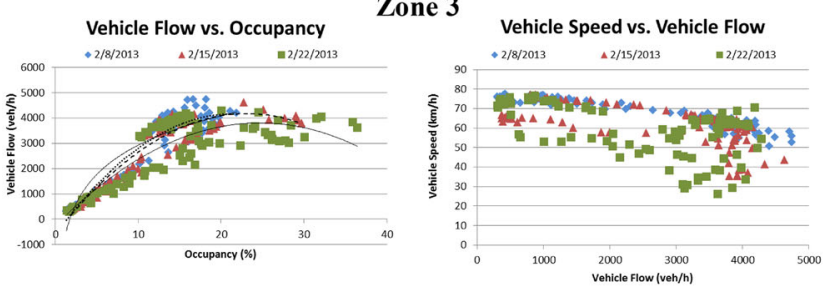

Zone 5
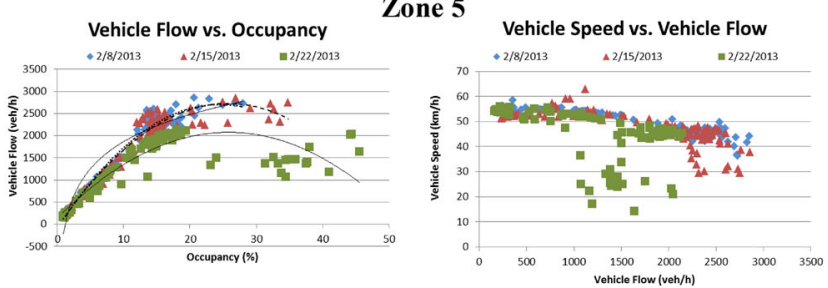

Zone 2

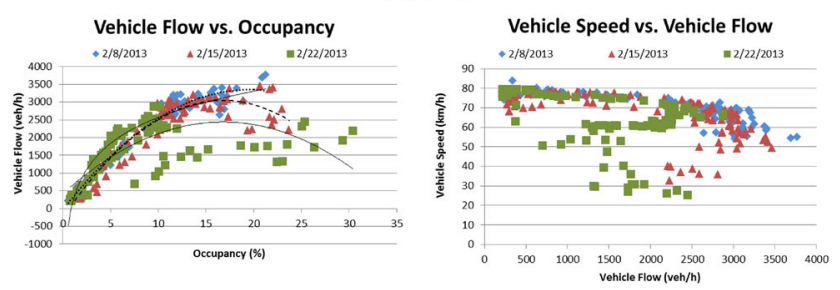

Zone 4
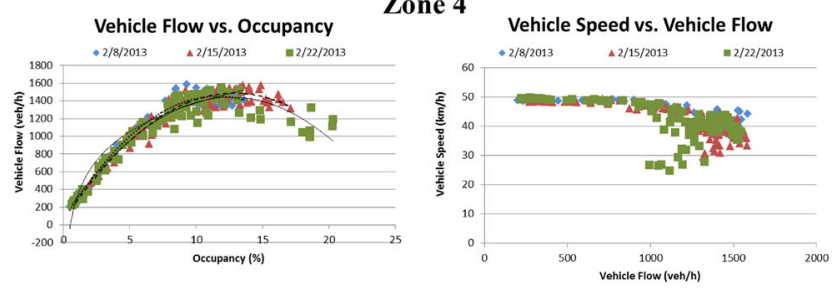

All other locations
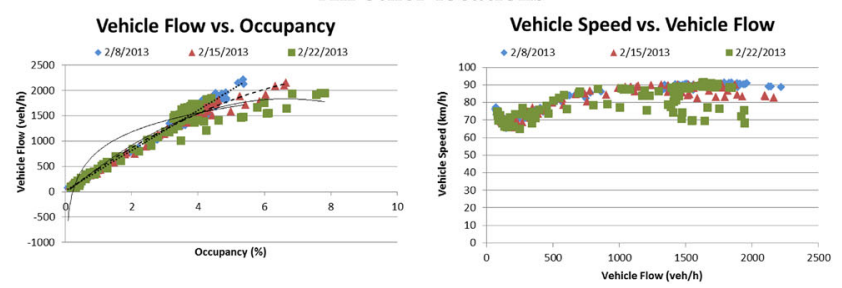

Fig. 5 Vehicle flow versus occupancy and vehicle speed versus vehicle flow diagrams per zone of analysis 
Zone 1

Vehicle Speed

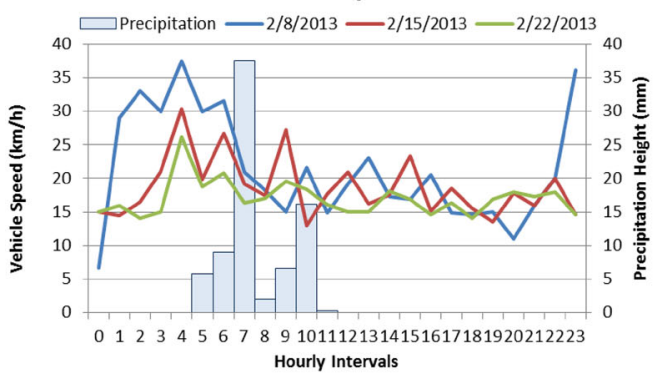

Zone 3

Vehicle Speed

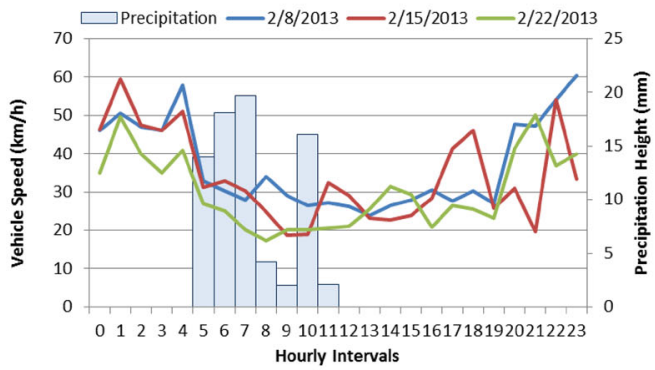

Zone 5

Vehicle Speed

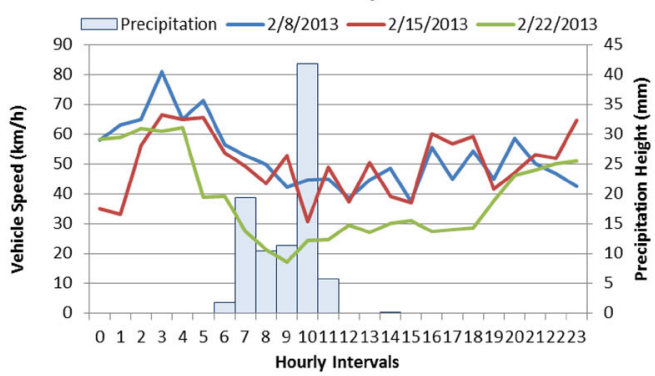

Zone 2

Vehicle Speed

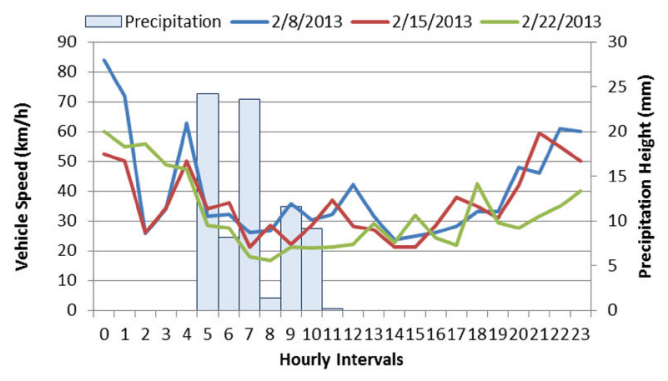

Zone 4

Vehicle Speed

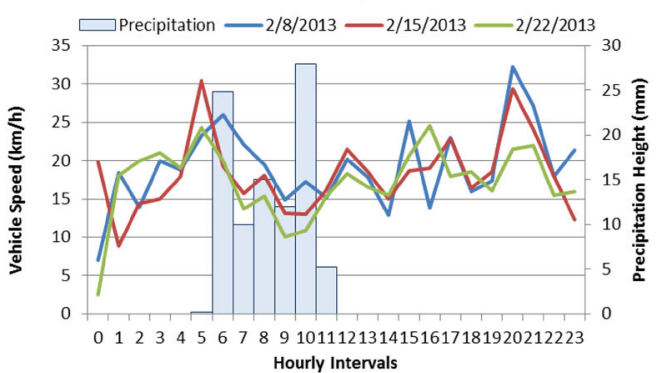

All other locations

Vehicle Speed

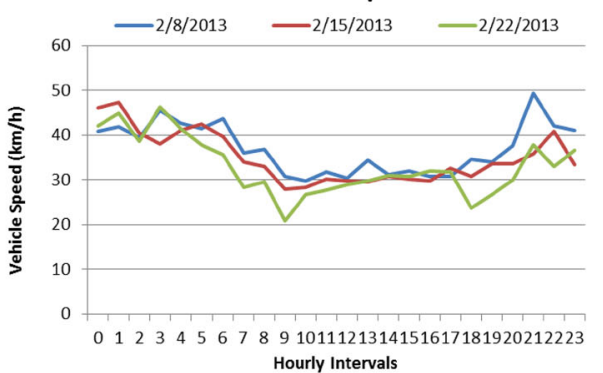

Fig. 6 Hourly speed analysis per study zone for freight vehicles

Table 3 Impact of rainfall on freight vehicle speed $(\mathrm{km} / \mathrm{h})$ and distance (vehicle-kilometers) traveled

\begin{tabular}{|c|c|c|c|c|c|c|c|}
\hline & \multicolumn{3}{|c|}{$\begin{array}{l}\text { Average daily freight } \\
\text { vehicle speed }(\mathrm{km} / \mathrm{h})\end{array}$} & \multirow[t]{2}{*}{$\begin{array}{l}\text { Average daily } \\
\text { difference }(\%)\end{array}$} & \multirow[t]{2}{*}{$\begin{array}{l}\text { Duration of } \\
\text { event's impact }\end{array}$} & \multirow[t]{2}{*}{$\begin{array}{l}\text { Average difference } \\
\text { during the event }(\%)\end{array}$} & \multirow[t]{2}{*}{$\begin{array}{l}\text { Maximum difference } \\
\text { during the event }(\%)\end{array}$} \\
\hline & $08 / 02 / 2013$ & $15 / 02 / 2013$ & $22 / 02 / 2013$ & & & & \\
\hline Zone 1 & 20 & 20 & 18 & -10 & $5: 00-8: 00$ & -10.7 & -34.8 \\
\hline Zone 2 & 33 & 33 & 27 & -18 & $5: 00-12: 00$ & -14.1 & -47.5 \\
\hline Zone 3 & 32 & 32 & 28 & -13 & $5: 00-12: 00$ & -15.6 & -49.3 \\
\hline Zone 4 & 20 & 20 & 18 & -10 & $5: 00-11: 00$ & -5.5 & -37.7 \\
\hline Zone 5 & 52 & 52 & 33 & -37 & $5: 00-19: 00$ & -23.1 & -67.8 \\
\hline \multirow[t]{3}{*}{ Athens Region } & 32 & 32 & 28 & -13 & - & -8.3 & -31.6 \\
\hline & \multicolumn{7}{|c|}{ Average distance traveled by freight vehicles (vehicle-kilometers) } \\
\hline & \multicolumn{2}{|c|}{ Zone 1} & Zone 2 & Zone 3 & Zone 4 & Zone 5 & Athens region \\
\hline $08 / 02 / 2013$ & \multicolumn{2}{|l|}{194} & 619 & 981 & 369 & 280 & 27.101 \\
\hline $15 / 02 / 2013$ & \multicolumn{2}{|l|}{160} & 627 & 1.025 & 366 & 315 & 27.143 \\
\hline $22 / 02 / 2013$ & \multicolumn{2}{|l|}{144} & 491 & 747 & 307 & 181 & 20.530 \\
\hline
\end{tabular}




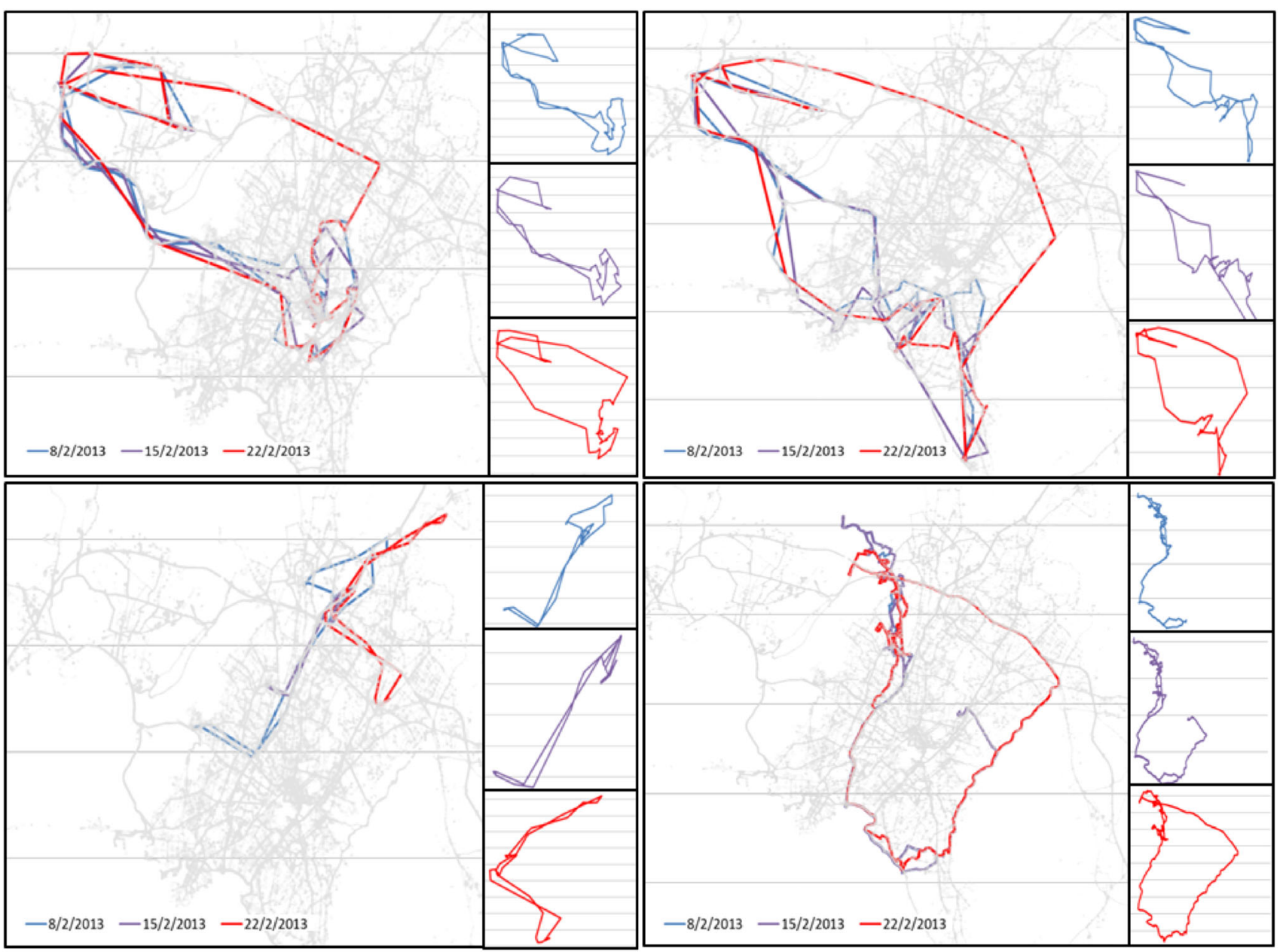

Fig. 7 Diverse freight vehicle detours due to flooding

of the differences are observed in certain zones. For instance, observed occupancies in Zone 2 and 3 behave oppositely to each other given the differences in vehicle flow and speed. This is due to the event's impact duration, in the sense of accumulated rainfall in the network, which continued to hinder transport operations in certain zones even after the rainfall was over. Overall, the average values of vehicle flow and speed reduction are consistent with those reported in the literature.

The MFD analysis in Fig. 5 shows a plot of vehicle flow and occupancy. Each point of the diagram represents average data taken over a 15 -min period during the 3 days. For the vehicle flow versus occupancy diagrams, it is noted that the data points fit into a curve, the top of which represents maximum flow in the area, given normal weather conditions (08/02/2013 and 15/02/2013). To the left of the maximum vehicle flow area are points observed under uncongested vehicle flow and points to the right (greater than approximately 15-20\% occupancy) represent congested flow, which as observed occurs on the day of the flooding event $(22 / 02 / 2013)$.
Plots of the vehicle speed versus vehicle flow using data taken from the same detectors clearly indicate two weather conditions; as weather grows more severe during the flooding, speeds are reduced, headways increase and flow is reduced.

Impacts on freight transport

The analysis presented next is based on an FCD for assessing the impacts of the flooding event on the circulation of freight vehicles and the evaluation of the operational disruptions that occurred on February the 22nd, 2013. In order to identify the impacts on an hourly basis, a speed analysis was conducted for all zones. Figure 6 depicts the results of the analysis.

The impact of the flooding event was considerably different on each study zone, ranging from lower impacts in Zone 1 to higher impacts in Zone 5, where the average speed dropped by up to $25 \mathrm{~km} / \mathrm{h}(67.8 \%$ difference $)$ during the course of the event. The duration of the impact was also different on each zone, ranging from 3 to $12 \mathrm{~h}$. 
Combining the duration and the severity of the impact, it can be concluded that Zone 1 was the least affected and Zone 5 the most affected one, while Zones 2, 3 and 4 present different combinations, with lower impact and larger duration or higher impact but shorter duration. A quantification of the speed drop (both for all days and during the event) is presented in Table 3, which summarizes the impact of the flooding on freight vehicle speed and the distance traveled by freight vehicles within the zones of analysis.

As observed, there is a significant average daily speed drop in the overall Athens region (up to $14 \%$ on average), which is higher when focusing on the study zones during the event (up to $>70 \%$ ). It is noted that the impact was higher in zones where the average daily speed was over $20 \mathrm{~km} / \mathrm{h}$. Fluctuations observed in vehicle speed between $08 / 02$ and $15 / 02$ in certain zones during particular time intervals are attributed to differing traffic conditions that might have occurred during these days.

At individual freight vehicle level, the analysis shows that certain regular routes of Friday the 22nd, 2013, were different compared to the preceding Fridays (08/02/13 and 15/02/13). Figure 7 depicts diverse detours of randomly selected freight vehicle routes due to the flooding event. The first two trucks significantly changed their routes, in order to avoid the most affected zones during the course of the event, while the regular route was re-established during the evening. The third truck avoided the affected zones.

Although the detours are obvious, leading to a higher distance travelled by the freight vehicles (in order to avoid closed roads or heavy congestion due to the rainfall) in all depicted cases, the overall distance traveled by the vehicle fleet is reduced, leading to the conclusion that a significant amount of planned trips were canceled or postponed due to the high-intensity storms.

\section{Conclusion}

This paper analyzes the impacts of a high-intensity storm on the transportation network of Athens, Greece. In order to determine the nature and the extent of the impact, this work examined different transport indicators using data from field detectors and FCD from freight vehicle fleets. The analyses revealed that the prevailing weather conditions, the intensity of rainfall and the resultant flooding on February the 22nd had a significant impact on the performance of the Athens transportation network. Detailed results showed increased travel times for all vehicles, significant changes in routing of freight vehicles and substantial speed drops, highlighting the disruptive effects of the flooding event on traffic.
Macroscopic fundamental diagrams based on observed data during or after adverse weather conditions or extreme events were used for quantifying the impact on traffic circulation. As data of that form are often available in real time, traffic management strategies and traffic flow control methodologies can be deployed in the sense of controlling traffic in the perimeter of the event, so as to minimize disruptions in the overall network performance.

Given that climate projections predict an increase in future climate variability, frequency and intensity of EWE, the present analysis provides a thorough qualitative and quantitative understanding of the potential future effects of climate change on urban transportation. An understanding that is particularly important, given that the projected growth of urban population has the potential to make such extreme hydrometeorologic phenomena in urban areas account for an increasing part of the total climate change impact.

Acknowledgments The work presented herein has been supported by the 7th Framework Program of the European Commission (FP7) under the MOWE-IT project. The authors would like to thank the Greek Fire Service for providing the emergency call data.

\section{References}

Alexouli-Livaditi A, Vouvalidis K, Livaditis G, Pechlivanidou S (2007) Drainage network characteristics of Athens plain at the end of the 19th century. Bull Geol Soc Greece 40(4):1513-1521

Amin MT, Alazba AA, ElNesr MN (2013) Adaptation of climate variability/extreme in arid environment of the Arabian peninsula by rainwater harvesting and management. Int $\mathrm{J}$ Environ Sci Technol 10:27-36

Bailey JF, Thomas WO, Wetzel KL, Ross TJ (1989) Estimation of flood-frequency characteristics and the effects of urbanization for streams in the Philadelphia, Pennsylvania area. U.S. Geological Survey Water-Resources Investigations Report 87-4194

Baloch MA, Ames DP, Tanik A (2014) Hydrologic impacts of climate and land-use change on Namnam Stream in Koycegiz Watershed, Turkey. Int J Environ Sci Technol. doi:10.1007/s/ 13762-014-0527-X

Baltas EA, Mimikou MA (2002) Considerations for the optimum location of a C-band weather radar in the Athens area. Proceedings of ERAD, pp 348-351

Barredo JI (2007) Major flood disasters in Europe: 1950-2005. Nat Hazards 42:125-148

Barrero JI (2009) Normalized flood losses in Europe: 1970-2006. Nat Hazards Earth Syst Sci 9:97-104

Brilon W, Ponzlet M (1996) Variability of speed-flow relationships on German autobahns. Transp Res Rec: J Transp Res Board 1555:91-96

Chang H, Lafrenz M, Won-Jung I, Figliozzi M, Platman D, Pederson C (2010) Potential impacts of climate change on flood-induced travel disruptions: a case study of Portland, Oregon, USA. Ann Assoc Am Geogr 100(4):938-952. doi:10.1080/00045608.2010. 497110

Dankers R, Hiederer R (2008) Extreme temperatures and precipitation in Europe: analysis of a high-resolution climate change scenario. 
Joint Research Centre Scientific and Technical Reports, Institute for Environment and Sustainability, Joint Research Centre, European Commission, Luxemburg

Diakakis M (2013) An inventory of flood events in Athens, Greece, during the last 130 years. Seasonality and spatial distribution. J Flood Risk Manag. Wiley. doi:10.1111/jfr3.12053

Diakakis M, Deligiannakis G (2013) Vehicle-related flood fatalities in Greece. Environ Hazards. doi:10.1080/17477891.2013.832651

Diakakis M, Foumelis M, Gouliotis L, Lekkas E (2011) Preliminary flood hazard and risk assessment in Western Athens Metropolitan area. In: Lambrakis N, Stournaras G, Katsanou K (eds) Advances in the research of aquatic environment, vol 1. Springer, Berlin, Heidelberg, pp 147-154

Diakakis M, Katsetsiadou K, Pallikarakis A (2013) Flood fatalities in Athens, Greece: 1880-2010. Bull Geol Soc Greece 47 (in press)

Easterling D, Meehl G, Parmesan C, Changnon S, Karl T, Mearns L (2000) Climate extremes: observations, modeling and impacts. Science 289:2068-2074

Eisenberg D, Warner KE (2004) The mixed effects of precipitation on traffic crashes. Accid Anal Prev 36:637-647

Fire Service (2013) Data on emergency calls received by the Greek Fire Service in Attica between the 22nd and 23rd February 2013. Greek Fire Service, Athens

Geroliminis N, Daganzo CF (2007) Macroscopic modeling of traffic in cities. 86th Annual meeting of the Transportation Research Board, Washington

Goodwin L (2002) Weather impacts on arterial traffic flow. The Road Weather Management Program FHWA, Washington

Hassan YA, Barker D (1999) The impact of unreasonable or extreme weather on traffic activity within Lothian region, Scotland. J Transp Geogr 7:209-213

Hollis GE (1975) The effect of urbanization on floods of different recurrence interval. Water Resour Res 11(3):431-435

Ibrahim AT, Hall F (1994) Effect of adverse weather conditions on speed-flow occupancy relationships. Transp Res Rec: J Transp Res Board 1457:184-191

James JD (1965) Using a digital computer to estimate the effects of urban development on flood peaks. Water Resour Res 1(2):223-234

Jonkman SN (2005) Global perspectives on loss of human life caused by floods. Nat Hazards 34:151-175

Koetse MJ, Rietveld P (2009) The impact of climate change and weather on transport: an overview of empirical findings. Transp Res Part D 14:201-205

Koutsoyiannis D, Baloutsos G (2000) Analysis of a long record of annual maximum rainfall in Athens, Greece, and design rainfall inferences. Nat Hazards 22(1):29-48

Lagouvardos K, Kotroni V, Koletsis I (2013) Storm entrapment and re-feeding in Athens: February the 22nd, 2013. National Observatory of Athens Announcement. http://4.bp.blogspot. com/2_GtxiMbJqw/USIT1JDbg5I/AAAAAAAAFVo/ BhzVoxn6a88/s1600/2013 02 22.bmp. Accessed 10 Oct 2013

Maze T, Agarwal M, Burchett G (2006) Whether weather matters to traffic demand, traffic safety and traffic operations and flow. Transp Res Rec: J Transp Res Board 1948:170-176

Meehl A, Thomas K, David R, Easterling D, Changnonc S, Pielke R Jr, Evanse J, Groismanb PY, Knutsonf TR, Kunkelc KE,
Mearnsa LO, Parmesang C, Pulwartyh R, Rooti T, Sylvesj RT, Whettonk P, Zwiersl F (2000) An introduction to trends in extreme weather and climate events: observations, socioeconomic impacts, terrestrial ecological impacts, and model projections. Bull Am Meteorol Soc 81:413-416

Mimikou M, Baltas E, Varanou E (2002) A study of extreme storm events in the Greater Athens area, Greece. Extrem Extraordin Floods 271:161-166

Mitsakis E, Stamos I, Papanikolaou A, Aifadopoulou G, Kontoes H (2013) Assessment of extreme weather events on transport networks: case study of the 2007 wildfires in Peloponnesus. doi:10.1007s11069-013-0896-3

Mitsakis E, Stamos I, Kral S, Doll C, Nokala M, Salanova Grau JM, Aifadopoulou G (2014) A data-driven method for assessing the resilience of the European passenger transport network during extreme weather events. To appear in Proceedings of the 93rd annual meeting of the Transportation Research Board, Washington

Monirul M, Mirza Q (2003) Climate change and extreme weather events: Can developing countries adapt? Clim Policy 3:233-248

Nikolaidou M, Hatzichristou E (1995) Registering and assessment of devastating floods in Greece and Cyprus, Thesis, Department of Water Resources, Hydraulic and Maritime Engineering, National Technical University of Athens, Athens, 1995

Norrman J, Eriksson M, Lindqvist S (2000) Relationship between road slipperiness, traffic accident risk and winter road maintenance activity. Clim Res 15:185-193

Paul MJ, Meyer JL (2001) Streams in the urban landscape. Annu Rev Ecol Syst 32:333-365

Perry AH, Symons LH (1991) Highway metrology. University of Wales, Swansea

Road Research Laboratory (1965) Research in road traffic. HMSO, London

Rosenzweig C, Iglesias A, Yang XB, Epstein P, Chivian E (2001) Climate change and extreme weather events; implications for food production, plant diseases, and pests. Glob Chang Hum Health 2(2):90-104

Sabir M, Van Ommeren J, Koetse MJ, Rietveld P (2008) Welfare effects of adverse weather through speed changes in car commuting trips. TI 2008-087/3, Tinbergen Institute Discussion Paper, VU University, Amsterdam

Skabardonis A, Kopelias P, Papadimitriou F (2013) Weather impacts on traffic flow. 6th International congress on transport research, Thessaloniki, Greece, 17-19 Oct 2013

Sohn J (2006) Evaluating the significance of highway network links under the flood damage: an accessibility approach. Transp Res Part A: Policy Pract 40(6):491-506

Suarez P, Anderson W, Mahal V, Lakshmanan TR (2005) Impacts of flooding and climate change on urban transportation: a systemwide performance assessment of the Boston Metro Area. Transp Res Part D: Transp Environ 10(3):231-244

Transportation Research Board (2010) Highway capacity manual. TRB, Washington 